\title{
The prehospital management of avalanche victims
}

\author{
Daniel K Kornhall, ${ }^{1,2,3,4,5}$ Julie Martens-Nielsen ${ }^{6}$
}

\begin{abstract}
${ }^{1}$ Anesthesia and Critical Care Research Group, UIT-The Arctic University of Norway, Tromsø, Norway

${ }^{2}$ Department of Internal Medicine, Helgeland Hospital Trust, Sandnessjoen, Norway ${ }^{3}$ East Anglian Air Ambulance, Marshall Airfield, Cambridge, UK

${ }^{4}$ Department of Anaesthesiology, University Hospital of North Norway, Tromsoe, Norway

${ }^{5}$ Svolvaer Alpine Rescue Group, Svolvaer, Norway

${ }^{6}$ Department of

Anaesthesiology, Hospital of Southern Norway, Kristiansand, Norway
\end{abstract}

\section{Correspondence to} Dr Daniel K Kornhall, The Air Ambulance Division of Emergency Medical Services, University Hospital of North Norway, 9038 Tromsø Norway; danielkornhall@me.com

Received 23 March 2015 Revised 31 May 2015 Accepted 1 June 2015 Published Online First 19 June 2015

\section{CrossMark}

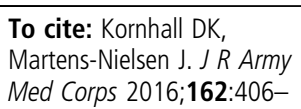

\section{ABSTRACT}

Avalanche accidents are frequently lethal events with an overall mortality of $23 \%$. Mortality increases dramatically to $50 \%$ in instances of complete burial. With modern day dense networks of ambulance services and rescue helicopters, health workers often become involved during the early stages of avalanche rescue. Historically, some of the most devastating avalanche accidents have involved military personnel. Armed forces are frequently deployed to mountain regions in order to train for mountain warfare or as part of ongoing conflicts. Furthermore, military units are frequently called to assist civilian organised rescue in avalanche rescue operations. It is therefore important that clinicians associated with units operating in mountain regions have an understanding of, the medical management of avalanche victims, and of the preceding rescue phase. The ensuing review of the available literature aims to describe the pathophysiology particular to avalanche victims and to outline a structured approach to the search, rescue and prehospital medical management.

The most frightening enemy was nature itself.... entire platoons were hit, smothered, buried without a trace, without a cry, with no other sound than the one made by the gigantic white mass itself. ${ }^{1}$

-Paolo Monelli, Italian author and journalist who during World War I saw service on the Austro-Italian front with the Alpini, the elite mountain corps of the Italian army.

\section{INTRODUCTION}

In Europe and North America avalanches kill approximately 150 persons annually, of which the majority are skiers, snowboarders and snowmobilers. ${ }^{2} 3$ Although a rare cause of death, avalanche deaths are particularly devastating as victims tend to be healthy individuals with a median age of 33 years. ${ }^{4}$ With modern-day dense networks of emergency helicopters and rescue services, health workers often become involved during the early stages of avalanche incidents. Avalanche medicine is highly relevant from a military clinician's perspective. Military units frequently practice mountain warfare and are often mobilised to assist civilian rescue operations. With the numerous ongoing global conflicts, armed forces are currently tasked to operate in mountain regions. Importantly, some of the most devastating avalanche accidents have involved military personnel. In 2012, a massive avalanche obliterated a Pakistani military camp on the Siachen glacier in northern Kashmir, killing 140 Pakistani soldiers and civilians. In 1986, an avalanche buried an entire platoon of Norwegian combat engineers participating in a winter warfare exercise in Vassdalen, Norway resulting in the
Key messages

Some of the most devastating avalanche accidents have involved military personnel.

- Military clinicians operating in mountain regions must have an understanding of the rescue phase as well as of the medical management of avalanche victims.

- Mortality in non-buried victims is very low. Mortality increases dramatically in victims who suffer complete burial.

- The majority of buried avalanche victims die of asphyxia, traumatic injury and hypothermia.

- Survival is inversely related to duration of burial. The majority of victims die within the first $30 \mathrm{~min}$.

- Avalanche rescue is a desperate race to extricate the victim in order to re-establish oxygenation and initiate medical management.

deaths of 16 conscripts and officers. ${ }^{5}$ During World War I, at least 60000 soldiers died in avalanches in the Austro-Italian Alps. Avalanche conditions were particularly critical during 17-19 December 1916, causing 9-10 000 lives to be lost. ${ }^{6}$ It follows that clinicians working in mountain regions must have an understanding of the medical management and the rescue components of avalanche accidents.

\section{METHOD}

A Pubmed search was performed using the MESH-term ("Avalanches"(Mesh)) OR "Snow"(Mesh)). This resulted in the initial identification of 1191 citations whose titles and abstracts were screened for eligibility. Articles were considered relevant if they described or commented on the pathophysiology and/or management of avalanche victims and were published in the English language. Fifty-nine articles were selected and subsequently subjected to full-text assessment. The reference lists of these articles yielded another 19 articles for in-depth assessment. Overall, 48/78 articles subject to full-text assessment were deemed relevant. As the ensuing work required discussing trauma and hypothermia management, specific high-quality references targeting these subjects were also enclosed.

\section{RESULTS}

\section{Avalanche mechanisms of injury and outcomes}

Avalanche accidents are frequently lethal with an overall mortality of $23 \% .^{2}$ Survival is primarily dependent on depth of burial, duration of burial, the severity of trauma and the presence of an air pocket and a patent airway. ${ }^{7}$ Of these, the depth of burial is the strongest determinant of survival. 
Completely buried victims suffer a mortality rate of roughly $50 \%$, while the mortality rate of non-buried victims drops to 3$4 \% .^{8} 9$ The vast majority of deaths in completely buried victims are caused by asphyxiation, trauma and hypothermia (Table 1). Of these, asphyxia is the predominant mechanism, causing $80 \%$ of avalanche related deaths. ${ }^{41011}$ Obviously, these mechanisms frequently coexist, further augmenting lethality. ${ }^{4}$

\section{Avalanche survival}

Survival is inversely related to duration of burial. This was demonstrated in 1994 by Falk et al, and in 2001 by Brugger et al, as they produced the now classic time-survival curve, describing survival probability in relation to duration of burial of a cohort of Swiss avalanche victims. The curve displays a characteristic phasic pattern where two initial steep drops in survival are followed by a more gradual decline. ${ }^{2} 12$ Similar curves were produced in 2011 when Haegeli et $a l^{9}$ published survival curves comparing Swiss and Canadian data (Figure 1). The initial steep drop is attributed to immediate trauma-related injury. Between $10 \mathrm{~min}$ and $20 \mathrm{~min}$, there is a plateau where roughly $80 \%$ of individuals remain alive followed by a second steep drop caused by deaths from asphyxiation leaving, in the Swiss sample, roughly $35 \%$ alive at $35 \mathrm{~min}$. After this, deaths occur at a slower rate as victims succumb to hypoxia, hypercapnia and hypothermia. ${ }^{9}$ Importantly, while the survival curves are similar, the Canadian sample documented lower survival rates at all durations of burial. This was attributed to greater trauma mortality and to the theory that the heavier and wetter Canadian snow promoted asphyxiation. ${ }^{9} 13$ The avalanche survival curve is a powerful representation of the grim challenge facing rescue services. To achieve acceptable outcomes, dispatch, location, extrication and commencement of treatment must occur promptly. On-scene cardiac arrest in buried avalanche victims has poor prognosis and survival is rarely associated with a favourable neurological outcome. ${ }^{14}$ In a recent review of 55 buried avalanche victims in cardiac arrest upon extrication, Moroder et al reported an overall mortality rate of $91 \%$ with only five survivors to hospital discharge. Of these, only two were discharged with a favourable neurological outcome. All five survivors had burial times $<20$ min. ${ }^{15}$ In 2014, Boue et al ${ }^{16}$ reviewed 48 avalanche victims who were admitted to intensive care after suffering on-scene cardiac arrest, documenting a mortality rate of $83.3 \%$ with eight survivors of which only three were discharged from hospital with a favourable neurological outcome.

\section{Asphyxia and hypoxia}

Airway occlusion is the leading cause of asphyxia and death in avalanche accidents. As depicted by the avalanche survival curve, the majority of deaths occur within the first half hour of burial and are thought to represent complete airway occlusion

Table 1 Reviews detailing causes of death from avalanches based on postmortem autopsy or full external examination ${ }^{4} 1011$

\begin{tabular}{llllll}
\hline Authors & Region & $\begin{array}{l}\text { Victims } \\
\text { included }\end{array}$ & Asphyxia & Trauma & Hypothermia \\
\hline $\begin{array}{l}\text { Boyd et al } \\
\text { Hohlrieder }\end{array}$ & Canada & 204 & $154(75 \%)$ & $48(24 \%)$ & $2(1 \%)$ \\
et al ${ }^{10}$ & Austria & 36 & $33(91.7 \%)$ & $2(5.5 \%)$ & $1(2.8 \%)$ \\
$\begin{array}{l}\text { Mclntosh } \\
\text { et al }{ }^{11}\end{array}$ & Utah, & 56 & $53(94.6 \%)$ & $3(5.4 \%)$ & $0(0 \%)$ \\
Total & & 296 & $240(81.1 \%)$ & $53(17.9 \%)$ & $3(1 \%)$ \\
\hline
\end{tabular}

from avalanche debris obstructing the airway. ${ }^{7}$ Cessation of respiration will result in cardiac arrest within approximately 10 min. $^{15}$ In a systematic review of avalanche case-control studies and case series, there were no reported survivors among those buried with an obstructed airway for longer than 35 min. ${ }^{17}$ Survival of buried victims beyond this 'asphyxiation phase' requires the presence of a patent airway and of an air pocket surrounding the victim's upper airway as this will allow for some degree of oxygenation. ${ }^{17}$ While evading immediate asphyxia, buried victims with a patent airway will instead face gradually developing hypoxia, hypercapnia and hypothermia; termed the 'triple $\mathrm{H}$ syndrome'. ${ }^{18}$ The rate at which these changes occur depends on the volume of the air pocket and on snow density, but may start occurring within minutes. ${ }^{19}$ Larger air pockets, such as can be formed by large blocks of snow in avalanche debris, will delay hypoxia and hypercapnia by containing more oxygen and by reducing $\mathrm{CO}_{2}$ rebreathing. ${ }^{19-21}$ Case reports document protracted survival of up to 2 days in victims with patent airways and access to large air pockets. ${ }^{22}$ The rate at which hypoxia develops has been shown to correlate to the air content of the surrounding snow, which in turn is a function of snow density. ${ }^{19}$ Snow density is defined as the overall mass of snow per unit volume. Dry, freshly fallen snow typically has a density of $30 \mathrm{~kg} / \mathrm{m}^{3}$ whereas density in wet spring snow is typically $600 \mathrm{~kg} / \mathrm{m}^{3}$, with a corresponding decrease in air content. The density of avalanche debris is commonly reported in the range of $200-600 \mathrm{~kg} / \mathrm{m}^{3} .^{23}$ Oxygen availability is further impaired by exhaled air condensing and freezing onto the surrounding snow, creating a layer of ice preventing diffusion of oxygen from the surrounding snow. Several case reports document pulmonary oedema in extricated avalanche victims, with literature suggesting that the incidence is under-reported. Negative pressure pulmonary oedema, hypoxic pulmonary artery vasoconstriction and hypoxic heart failure have been postulated as plausible underlying mechanisms. ${ }^{24-26}$ Finally, the weight of the covering snow may cause chest restriction and impaired breathing. ${ }^{27}$

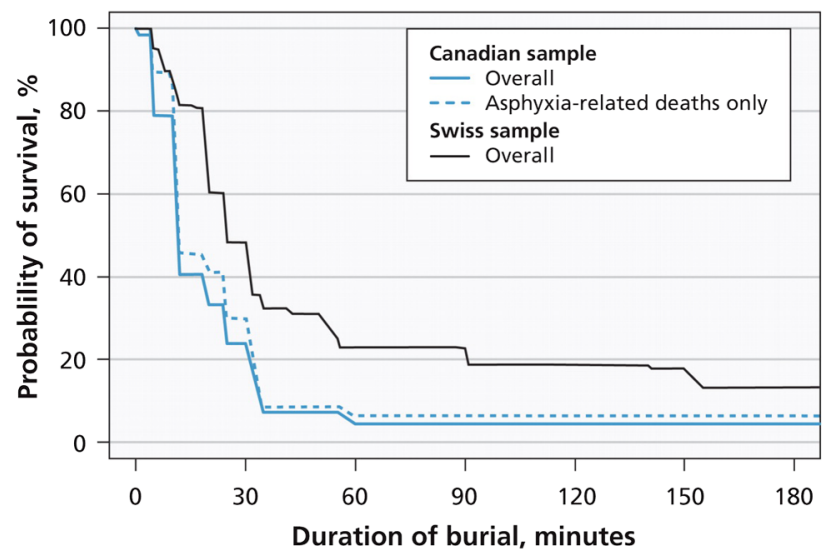

Figure 1 The avalanche survival curve plots survival of buried avalanche victims against duration of burial. It displays a characteristic phasic pattern where two steep drops in survival is seen during the first half hour after which death occurs much more slowly. The steep drops are explained by immediate trauma deaths and asphyxiation. This version of the avalanche survival curve, by Haegeli et al in 2011, ${ }^{9}$ compares Canadian and Swiss survival. Mortality in the Canadian sample is greater at all burial durations. This has been attributed to greater trauma mortality in Canada and to how heavier and wetter snow in the Canadian sample could promote asphyxiation. Reprinted with permission. 
Trauma

The severity and mortality of traumatic avalanche injuries display considerable regional variation (Table 1). Few studies report reliable causes of death based on thorough clinical examination and autopsy findings. In an Austrian study of hospitalised avalanche victims, 27/105 (25.7\%) had moderate to critical injury corresponding to an injury severity score of 8 or higher; the authors attributed 2 of the $36 \quad(5.4 \%)$ avalanche-related deaths to trauma. ${ }^{10}$ Identical trauma mortality was reported from Utah by McIntosh et al, ${ }^{11}$ but these data should be contrasted to Canadian data from coroners' reports of 204 avalanche deaths where a third of all non-survivors had suffered major trauma and 24\% of deaths were primarily attributed to trauma. ${ }^{4}$ These differences in trauma morbidity and mortality are likely explained by regional variations in topography and snow composition. ${ }^{28}$ Avalanches consisting of wet and heavy snow, tracking over forested or rocky terrain generally cause more traumatic injury than dry powder avalanches tracking over open snowfields above the tree line. ${ }^{2}$ Based on clinical examination and autopsy studies, avalanche victims frequently display head, spine, chest and limb injuries. ${ }^{10}{ }^{11}$ In the Canadian data, chest and head trauma represented $46 \%$ and $42 \%$, respectively, of single-system injury. ${ }^{4}$

\section{Hypothermia}

Hypothermia can be defined as a core body temperature below $35^{\circ} \mathrm{C}$ and is considered a rare cause of death in avalanche victims. $^{29}$ Nevertheless, it is a common complication and a medical emergency that must be anticipated and treated aggressively. $^{30}$ Avalanche victims may develop hypothermia rapidly, with documented mean cooling rates ranging from $0.8^{\circ} \mathrm{C} / \mathrm{h}$ to $3^{\circ} \mathrm{C} / \mathrm{h},{ }^{18}{ }^{31}$ although individual case studies report extreme cooling rates of up to $9^{\circ} \mathrm{C} / \mathrm{h}^{24} 3233$ The presence of hypercapnia will increase the rate of cooling, primarily by inducing hyperventilation and respiratory heat loss. ${ }^{18} 34$ As endogenous production of heat through metabolism and shivering requires oxygen, hypoxia will also accelerate cooling. ${ }^{35}$ Importantly, extrication and evacuation contributes to additional heat loss. Snow has insulating properties and upon extrication, victims are exposed to further heat loss, unless immediately insulated and rewarmed. ${ }^{36}$ Unfortunately, postextrication cooling frequently occurs despite countermeasures. This paradoxical worsening of hypothermia during attempts at rewarming is termed 'afterdrop'. After-drop is a manifestation of rewarming causing reduced peripheral vasoconstriction followed by cold peripheral blood mixing with the warmer central circulation. The net effect is increased peripheral heat loss and core cooling. The rate of cooling may transiently increase by up to four times. ${ }^{37}$ Additionally, accidental hypothermia may result in circumrescue collapse, defined as sudden death or circulatory collapse during or after rescue, caused by the sudden onset of ventricular fibrillation or worsening cardiac failure. ${ }^{38}$

\section{Avalanche search and rescue}

As the majority of victims die of asphyxia, the overarching priority is to quickly locate and extricate the victim, followed by the immediate re-establishment of airway patency and oxygenation. Avalanche rescue can be said to consist of two phases; the rescue of the victim followed by the medical management. ${ }^{39}$ The rescue phase includes the notification and dispatch of rescue services, location of the victim and, finally, extrication. The medical phase consists of medical management and transfer to definite care. As is evident from the avalanche time-survival curve, prolonged rescue is associated with poor outcomes. Ideally, bystanders should promptly initiate search and extrication. Even with immediate dispatch, the deployment of organised rescue is time-consuming and the initial window of survivability is often lost. ${ }^{15}$ The majority of survivors are located by companions relying on visual cues and avalanche transceivers. ${ }^{40}$ From the European Alps and Canada, mean extrication times of $18-35$ min have been reported. ${ }^{8}{ }^{9}$ In 2005 Slotta-Bachmayr et al reported significantly shorter extrication times for rescue instigated and completed by companions as opposed to when completed by organised rescue teams, at 16 min vs 150 min. ${ }^{41}$ Consequently, companion rescue dramatically improves survival, with reported survival rates of $74-78 \%$ compared with $18-19 \% .^{40}$ 42 Delayed extrication is commonly caused by the avalanche being unwitnessed or by whole groups being caught. Poor weather conditions, restricted helicopter access, extreme depths of burial and unacceptable avalanche conditions may also preclude or delay rescue. ${ }^{43}$

\section{Locating the buried avalanche victim}

Several devices have been developed to increase avalanche survival, by reducing asphyxiation through minimising depth and duration of burial or by preventing asphyxiation after burial. ${ }^{8}$ Appropriate clothing, snow shovels, avalanche transceivers and avalanche probes is essential equipment for skiers and rescuers active outside prepared ski areas. ${ }^{7}$ The avalanche airbag is designed to prevent or reduce depth of burial. It consists of a backpack integrating a gas cartridge connected to one or two 120-150 L balloons. As the skier activates the cartridge, the balloons inflate. The device relies on the theory of 'granular convection', which dictates that larger particles will deposit in the upper layers of a granular material in motion. As the skier inflates the balloons he or she will become a larger 'particle', thus reducing the depth of burial. In a Swiss study from 2007, Brugger et al reviewed 1504 avalanche victims wearing avalanche airbag systems. The mortality rate in the subgroup that was wearing airbags was 3\% compared with $19 \%$ for the victims not using an airbag system. In $20 \%$ of cases the airbag system never deployed due to technical error or the victim being unable to activate the device. ${ }^{8}$ In a 2014 review of international avalanche victim data, Haegeli et $a l^{44}$ reported an absolute mortality reduction from $22 \%$ to $11 \%$; again, failure rates of $20 \%$ were documented. The artificial air pocket (AvaLung; Black Diamond Equipment, Salt Lake City, Utah, USA) is designed to prolong survival during snow burial. It consists of a mouthpiece and respiratory tubing connected to a mesh air pocket worn in a vest. Air is extracted from the snow via the artificial air pocket and is inhaled through the tubing. The respiratory tubing then separates inhaled and exhaled gases, with expired gas being conveyed towards the back of the victim, thereby limiting carbon dioxide rebreathing. While there is no clinical outcome data in support of this system, the system reliably attenuates hypoxia and hypercapnia in field tests. ${ }^{20}$ The avalanche transceiver is a radio beacon capable of transmitting and receiving radio waves at $457 \mathrm{kHz}$. It allows rescuers equipped with transceivers to locate buried victims equipped with transmitting transceivers. In 2005, Hohlrieder et al ${ }^{45}$ reported a decrease in mean duration of burial from $102 \mathrm{~min}$ to 20 min for victims using transceivers, associated with a mortality reduction of $14.2 \%$. In a similar retrospective study from 2007, a decrease in duration of burial from $125 \mathrm{~min}$ to $25 \mathrm{~min}$ was documented with an associated mortality reduction of $15.2 \% .^{8}$ The avalanche probe is a collapsible $2-3 \mathrm{~m}$ long multisectioned aluminium rod designed to penetrate compacted snow 
in order to locate buried victims. Often, the victim is roughly located using an avalanche transceiver followed by pinpointing the victim's exact location and depth of burial using a probe. However, some victims may not have transceivers or carry non-functioning transceivers. These victims may be found by probe-lines where rescuers form a line to systematically probe the area ahead. This method is time-consuming and requires considerable manpower. Teams of avalanche dogs and handlers form an integral part of avalanche rescue in many areas as they can cover larger areas in shorter time and are quicker to deploy than probe-lines. A review of organised rescue in 217 avalanche incidents demonstrated avalanche dogs to be superior to transceivers and probe-lines in locating buried avalanche victims alive. $^{41}$

\section{Extrication}

Survival and time to extrication correlates with depth of burial $^{43}$ which can vary considerably with mean depths of burial of $80-150 \mathrm{~cm}$ reported. ${ }^{2}{ }^{12}$ Extreme burial depths below $200 \mathrm{~cm}$ are generally associated with terrain traps where masses of snow tend to deposit. ${ }^{46}$ Poor shovel quality and suboptimal digging strategies prolong extrication. ${ }^{47}$ Upon locating the victim with an avalanche probe, untrained rescuers tend to dig straight down along the probe-line. This is inexpedient as it creates a cone-shaped vertical hole where the clearing of snow is difficult and inefficient, as snow tends to fall back over the victim. Additionally, this strategy may result in rescuers stepping on the victim, which may compromise the victim's air pocket, airway or chest; it may also worsen or cause traumatic injury. ${ }^{36}$ When access is finally achieved, a small diameter access hole makes it difficult or impossible to treat, roll and/or extricate the victim. With novel extrication techniques, digging commences downhill of the probe with the rescuers digging at an angle towards the victim. Snow is more efficiently removed downhill, the rescuers avoid stepping on the victim and the air pocket is more likely to remain preserved. Manuel Genswein's 'V-shaped conveyor belt' method exemplifies a modern digging technique. The rescuers form a $\mathrm{V}$ with one rescuer digging towards the victim at the apex while the remaining rescuers remove snow down the downhill conveyor belt legs. Positions are rotated as the front digger becomes fatigued. In field tests, this method achieved extrication at roughly half the time of that required by means of unstructured digging, with efficiency increasing with increasing burial depths. ${ }^{48}$ The victim's body position determines access to the airway and chest. Importantly, when exposing the victim's face the presence of an air pocket and the patency of the airway must be determined as this will guide immediate medical management. ${ }^{36}$

\section{Prehospital medical management}

The medical management of avalanche victims may include airway support, resuscitation and management of a wide range of traumatic injuries as well as hypothermia. The median number of victims in avalanche incidents, buried or non-buried, is four. ${ }^{22}$ Prehospital and mountain rescue assets are limited and must not be spent on futile interventions. Medical management is dictated by team safety. Avalanche rescue operations are frequently conducted under conditions with considerable avalanche danger. ${ }^{40} 42$ The potential for new avalanches, dangerous terrain, exposure to poor weather and low temperatures may pose unacceptable hazards to rescuers and bystanders. Medical management should, like rescue operations, be scaled accordingly. In some instances medical intervention must be modified or delayed until after complete evacuation, or even withheld. ${ }^{49}$
Immediate actions

A basic assessment of the victim should be performed as soon as access is gained. Detecting signs of life in patients with severe hypothermia may be difficult as ventilatory effort and cardiac pulsations may be weak, slow and irregular. Airway management, ventilatory support or cardiac compressions may have to be initiated before extrication is complete. ${ }^{7}$ Supplemental oxygen should be provided. ${ }^{36}$ Spinal precautions should be taken as spinal injuries are a common cause of morbidity and death. ${ }^{10} 36$ The victim should be handled gently and kept in a horizontal position throughout the extrication and rescue as patients with hypothermia may develop circulatory collapse upon mechanical stimuli. ${ }^{50}$ Ideally, the victim is extricated directly onto an insulated stretcher for immediate protection from wind, cold and precipitation. The victim should be covered in insulating materials, such as sleeping bags, blankets or bubble wrap. ${ }^{2}$ Significant heat can be lost from the head and neck, hence particular care must be taken to protect these parts. ${ }^{51}$ While wet clothes cause evaporative heat loss, their removal may worsen hypothermia by increasing elemental exposure. Instead, evaporative heat loss may be minimised by adding an airtight vapour barrier immediately outside the wet clothing. ${ }^{52}$ Recent studies have suggested that the optimal packaging method for wet conditions is a combination of a vapour-tight inner layer followed by a dry insulating middle layer covered in a wind-resistant and water-resistant outer wrapping. ${ }^{53} 54$ Obtaining vascular access may be difficult due to hypothermic and/or hypovolaemic vasoconstriction. Intraosseous access is a fast and reliable alternative to intravenous cannulae. ${ }^{55}$ Basic monitoring includes ECG monitoring and core body temperature measurement. Pulse oximetry may be inaccurate because of peripheral vasoconstriction or malfunction due to high altitude, cold and ambient light. ${ }^{56}$ Core body temperature measurements should be obtained unless it is unlikely to impact on management. ${ }^{36}$ Core body temperature is most reliably obtained by oesophageal probe measurement in the lower third of the oesophagus and should be used in intubated patients. ${ }^{57}$ In nonintubated patients, thermistor-based tympanic thermometers are recommended. ${ }^{58} 59$ If temperature measurements cannot reliably be obtained, one should assume a worst-case cooling rate and accept the potential for severe hypothermia despite short duration of burial. ${ }^{7}$

\section{Initial triage of avalanche victims in cardiac arrest}

Evidence-based guidelines for the triage and resuscitation of avalanche victims have been issued. ${ }^{36}$ Resuscitation may be withheld when victims in cardiac arrest display irreversible lethal injuries or where the body is frozen to the degree that it precludes effective chest compressions. ${ }^{49}$ Current guidelines also acknowledge that survival of avalanche victims with burial duration beyond $35 \mathrm{~min}$ requires the presence of a patent airway. ${ }^{17}$ Consequently, life may be pronounced extinct in victims buried for longer than $35 \mathrm{~min}$ who are found with an airway that is obstructed by snow or other debris (Figure 2). ${ }^{36}$ In these victims, asphyxiation should be assumed to have ensued upon burial, followed by cardiac arrest shortly thereafter. On the other hand, cardiopulmonary resuscitation (CPR) should be initiated in all other victims where the duration of burial is less than $35 \mathrm{~min}$ as resuscitation may be successful, with or without the presence of a patent airway. Resuscitation should also commence in victims found with a patent airway, irrespective of duration of burial. ${ }^{36}$ A patent airway permits survival beyond the asphyxiation phase. Hence, the time of cardiac 
arrest before extrication cannot be estimated with any certainty. Survival beyond the asphyxia phase also means there is a possibility of hypothermia emerging as the primary cause of cardiac arrest.

\section{Resuscitation of avalanche victims in cardiac arrest}

Patients who may benefit from CPR should receive standard resuscitation with ventilations as soon as rescuers gain access to the victim's airway and chest. ${ }^{36}$ As hypoxia is the likely aetiology, compression-only CPR is insufficient. ${ }^{36}$ Mechanical compression devices may be used. While there is no evidence that they improve outcomes, they will reduce rescuer fatigue in situations with limited personnel and may facilitate compressions during evacuation. ${ }^{6061}$ Because asphyxia, hypoxia and trauma are the main causes of cardiac arrest, the presenting ECG rhythm is commonly asystole or pulseless electrical activity. ${ }^{62} 16$ Defibrillation may be required, but is rarely successful in victims with core body temperatures below $28^{\circ} \mathrm{C} .{ }^{24}$ Vasoactive and antiarrhythmic drugs may also be ineffective in patients with hypothermia with core body temperature below $<30^{\circ} \mathrm{C} .^{38}$ Importantly, reversible causes of traumatic cardiac arrest, such as hypovolaemia and tension pneumothorax, must be considered and appropriately treated. ${ }^{63}$ In normothermic cardiac arrest victims, resuscitation may be terminated after $20 \mathrm{~min}$, in accordance with standard CPR guidelines. ${ }^{36}$

\section{Extracorporeal circulatory rewarming and continuous CPR in hypothermic avalanche cardiac arrest}

Current guidelines recommend a further triage decision point after core body temperature is estimated or measured. The oxygen requirement of tissues, the brain in particular, is dramatically reduced in hypothermia. ${ }^{64}$ Case series and case reports describe non-asphyxiated hypothermia victims, including avalanche victims, who have survived extended periods of cardiac arrest with full neurological recovery after prolonged resuscitation during invasive rewarming. ${ }^{17} 24 \quad 65-68$ Individual case reports describe survival even in instances where CPR has been inefficient or withheld. ${ }^{24} 65$ Consequently, guidelines recommend that hypothermic avalanche victims in cardiac arrest with a patent airway upon location and core body temperature below $32^{\circ} \mathrm{C}$ receive continuous $\mathrm{CPR}$ until rewarmed. These victims require invasive hospital rewarming and are ideally transferred to a hospital with extracorporeal circulatory support (ECC) capability for circulatory support and rapid rewarming. ${ }^{36}$ However, routine use of ECC rewarming in hypothermic avalanche victims in cardiac arrest is associated with extremely poor outcomes, inferior to outcomes in pure hypothermic cardiac arrest. ${ }^{2}$ Few survivors are reported, of which nearly all suffered cardiac arrest after extrication and had extremely low core body temperatures at $<24^{\circ} \mathrm{C}$, suggesting hypothermia rather than asphyxia as the primary cause of cardiac arrest. ${ }^{14}$

\section{Advanced life support in avalanche survivors}

The prehospital management of living avalanche victims may be guided by existing advanced trauma life support guidelines. On-site medical management must be efficient and should not unnecessarily delay evacuation. ${ }^{36}$ Established systems such as Pre Hospital Trauma Life Support (PHTLS), Advanced Trauma Life Support (ATLS) or Battlefield Advanced Trauma Life Support (BATLS) dictate a systematic and sequential approach to the assessment and management of airways and spine control, breathing and ventilation, circulation and haemorrhage control, disability and exposure. ${ }^{69-71}$

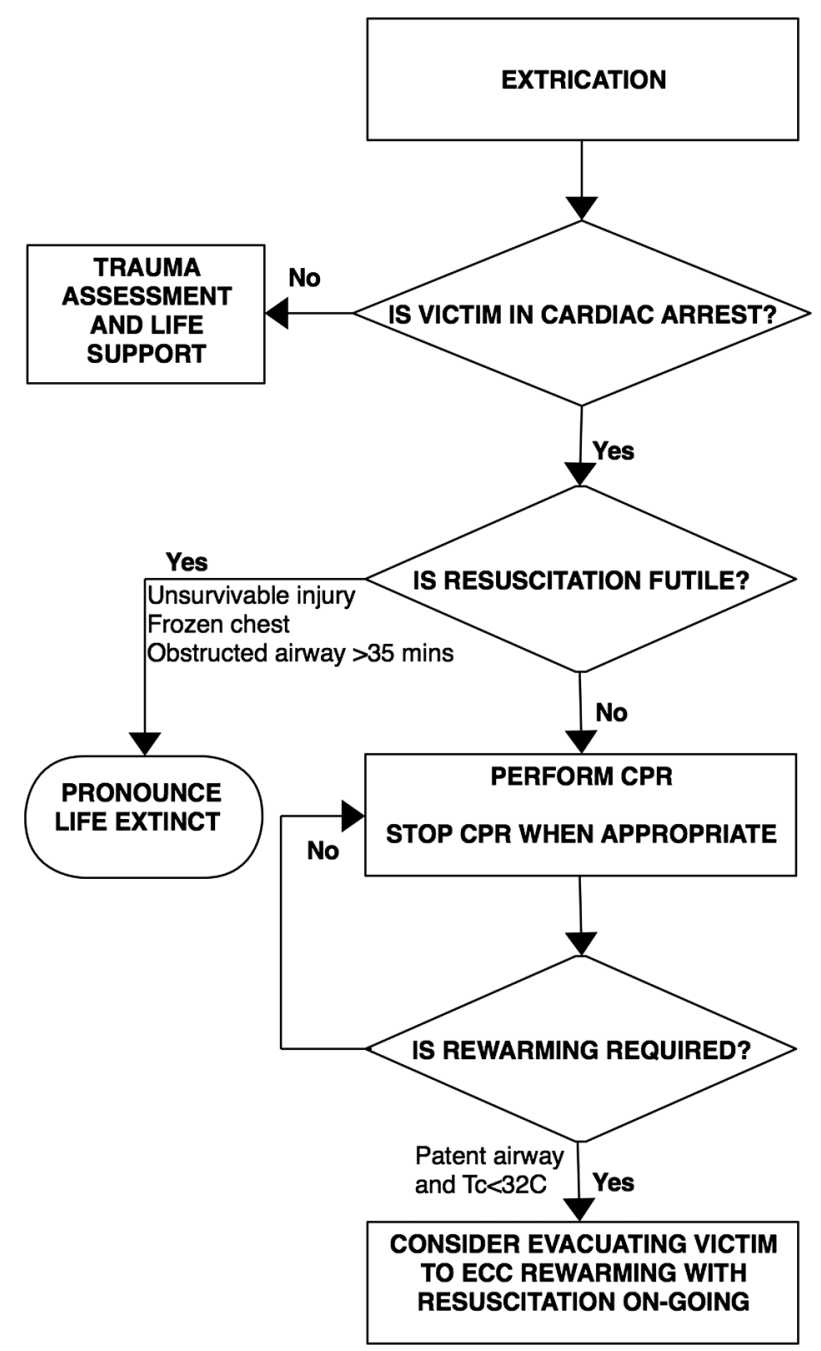

Figure 2 Algorithm describing the triage decision making process for avalanche victims in cardiac arrest. CPR, cardiopulmonary resuscitation; ECC, extracorporeal circulatorysupport.

\section{Managing hypothermia in avalanche victims}

Staging systems have been developed to facilitate treatment of accidental hypothermia. ${ }^{38}$ One such staging system is the Swiss hypothermia classification system (abbreviated to HT). Instead of relying on temperature measurements, this system is based on clinical observations including decreasing levels of consciousness, loss of shivering and loss of vital signs, as is observed with increasing hypothermia. Hence, HT circumvents problems associated with temperature measurements as well as individual variations in manifestations of hypothermia. ${ }^{72}$ After staging hypothermia, a recommendation on the appropriate management can be made (Table 2). ${ }^{73}$ Guidelines for accidental hypothermia, however, are not easily applied to avalanche victims where asphyxia and trauma frequently coincide. Instead, the approach must be tailored to the individual victim. Ideally, a core temperature is obtained which aids in determining appropriate treatment. ${ }^{36}$ Rewarming should nevertheless be initiated on-scene in order to attenuate further cooling and after-drop. ${ }^{38}$ Exogenous heat sources, such as chemical or electrical heat pads and blankets may be applied to the axillae, chest and back where conductive heat transfers most efficiently. ${ }^{74}$ Bolus administration of fluids warmed to $40-42{ }^{\circ} \mathrm{C}$ will prevent further core body temperature cooling from continuous fluid infusions, but will only marginally rewarm. ${ }^{38}$ 
Table 2 The Swiss hypothermia staging system with recommendations for management

\begin{tabular}{|c|c|c|c|c|}
\hline HT stage & Clinical signs & $\begin{array}{l}\text { Core } \\
\text { temperature }\end{array}$ & Management & Hospital triage \\
\hline $\begin{array}{l}\text { HT I } \\
\text { Mild } \\
\text { hypothermia }\end{array}$ & Conscious and shivering. & $35-32^{\circ} \mathrm{C}$ & $\begin{array}{l}\text { Active movement and mobilisation } \\
\text { - Supply warm and sweetened fluids } \\
\text { Insulate and protect from the elements. }\end{array}$ & Nearest hospital with emergency department. \\
\hline $\begin{array}{l}\text { HT II } \\
\text { Moderate } \\
\text { hypothermia }\end{array}$ & $\begin{array}{l}\text { Reduced consciousness and not } \\
\text { shivering. }\end{array}$ & $<32-28^{\circ} \mathrm{C}$ & $\begin{array}{l}\text { Gentle extrication and horizontal } \\
\text { immobilisation. } \\
\text { Establish ECG and core temperature } \\
\text { monitoring. } \\
\text { Apply active external warming to chest, } \\
\text { axillae and back. } \\
\text { Administer oxygen. } \\
\text { Obtain intravenous or intraosseous access } \\
\text { without delaying transport. } \\
\text { Insulate and protect from the elements. }\end{array}$ & $\begin{array}{l}\text { Stable haemodynamics: } \\
\text { Hospital with active rewarming capability. } \\
\text { Unstable haemodynamics: } \\
\text { Triage to hospital with ECMO/CPB capability for } \\
\text { circulatory support and rewarming. }\end{array}$ \\
\hline $\begin{array}{l}\text { HT III } \\
\text { Severe } \\
\text { hypothermia }\end{array}$ & $\begin{array}{l}\text { Unconscious and not shivering but } \\
\text { vital signs are present. }\end{array}$ & $<28-24^{\circ} \mathrm{C}$ & $\begin{array}{l}\text { As above plus } \\
\text { Airway management: Recovery position or } \\
\text { advanced airway management. } \\
\text { - Avoid depolarising agents (Possible } \\
\text { hyperkalaemia). } \\
\text { - Carefully dose or withhold drugs. }\end{array}$ & $\begin{array}{l}\text { Stable haemodynamics: } \\
\text { Hospital with active rewarming capability. } \\
\text { Unstable haemodynamics: } \\
\text { Triage to hospital with ECMO/CPB capability for } \\
\text { circulatory support and rewarming. }\end{array}$ \\
\hline $\begin{array}{l}\text { HT IV } \\
\text { Profound } \\
\text { hypothermia }\end{array}$ & No vital signs. & $<24^{\circ} \mathrm{C}$ & $\begin{array}{l}\text { As above plus } \\
\text { Standard CPR. } \\
\text { Avoid excessive attempts at defibrillation. }\end{array}$ & $\begin{array}{l}\text { Triage to hospital with ECMO/CPB circulatory } \\
\text { support and rewarming. }\end{array}$ \\
\hline
\end{tabular}

Adapted from Brugger et $a l^{36}$ and Durrer et $a l^{72}$ In avalanche victims the clinical presentation of hypothermia may be distorted by the possible coexistence of trauma and asphyxia.

$\mathrm{CPB}$, cardiopulmonary bypass; CPR, cardiopulmonary resuscitation; ECMO, extracorporeal membrane oxygenation.

\section{Evacuation and hospital triage}

Helicopter evacuation is the preferred method of retrieving avalanche victims, but may be unavailable due to mechanical failure, poor weather conditions or unacceptable scene safety. ${ }^{39}$ Rescuers may have to rely on snowmobiles, land ambulances or stretcher evacuation by foot. Hospital destination will be decided by the victim's clinical condition and regional hospital availability. Given the high incidence of traumatic injury, most avalanche victims should be transferred to a dedicated trauma centre, unless significant injury can be ruled out with certainty. ${ }^{9}{ }^{70}$ Victims with moderate to severe hypothermia are likely to require active hospital rewarming. Victims with a core temperature $<32^{\circ} \mathrm{C}$ that are haemodynamically unstable should ideally be transferred to a facility with ECC support and rewarming. ${ }^{36}$ As detailed above, avalanche victims without vital signs should be transferred directly to a centre with ECC capability for rewarming and resuscitation as long as they are hypothermic with a core temperature $<32^{\circ} \mathrm{C}$ and were found with a patent airway and an air pocket. Cardiac arrest victims who are successfully resuscitated should be transferred to a hospital with Intensive Care Unit (ICU) capability. ${ }^{36}$

\section{CONCLUSION}

Some of the most devastating avalanche accidents have involved military personnel. Armed forces frequently train or are deployed to mountain regions, exposing them to avalanche danger. Furthermore, they are often called to assist civilian rescue services in avalanche accidents. Clinicians attached to such units, must have a solid understanding of avalanche search and rescue as well as the medical management of victims. Buried avalanche victims suffer a mortality rate of roughly $50 \%$ of which the majority die of asphyxia, followed by trauma and hypothermia. As demonstrated by the avalanche survival curve, survival rates fall dramatically during the first half hour of complete burial, leaving roughly $35 \%$ of victims alive after $35 \mathrm{~min}$. Emergency dispatch, victim location, extrication and medical management becomes a desperate race to re-establish oxygenation and to stabilise victims. Numerous devices have been developed to increase survival in avalanche accidents. Snow shovels, snow probes and avalanche transceivers are considered essential personal equipment for avalanche rescuers. A more recent innovation is the avalanche airbag that is designed to prevent burial or reduce burial depth if successfully deployed. The localisation of buried victims who are not found by bystanders or transceivers often relies on organised rescue operations deploying probe-lines and avalanche dogs. After locating the victim, it is of vital importance to have an efficient strategy for extrication as this will greatly affect burial duration. Several techniques for strategic digging have been developed and some have proven their superiority in field tests. The medical management of extricated avalanche victims can be challenging. The clinician must be prepared to manage victims who are critically ill or in cardiac arrest. While reversing asphyxia and hypoxia is given priority the clinician must also be prepared to manage hypothermia as well as a wide range of traumatic injury.

Competing interests None declared.

Provenance and peer review Not commissioned; externally peer reviewed.

\section{REFERENCES}

1 Monelli P, Williams O. Toes up; a chronicle of gay and doleful adventures of Alpini and mules and wine. New York: Harcourt, 1930.

2 Brugger $\mathrm{H}$, Durrer B, Adler-Kastner L, et al. Field management of avalanche victims. Resuscitation 2001:51:7-15.

3 Jamieson B, Stethem C. Snow avalanche hazards and management in Canada: challenges and progress. Nat Hazards 2002;26:35-53.

4 Boyd J, Haegeli P, Abu-Laban RB, et al. Patterns of death among avalanche fatalities: a 21-year review. CMAJ 2009;180:507-12.

5 Karstein L. The avalanche accident at Vassdalen, Norway, 5 March 1986. Cold Reg Sci Technol 1988;15:137-50.

6 Lichem HV. Gebirgskrieg, 1915-1918. Bozen: Athesia, 1980.

7 Brugger $\mathrm{H}$, Paal P, Boyd J. Prehospital resuscitation of the buried avalanche victim. High Alt Med Biol 2011;12:199-205.

8 Brugger $\mathrm{H}$, Etter $\mathrm{HJ}$, Zweifel $\mathrm{B}$, et al. The impact of avalanche rescue devices on survival. Resuscitation 2007;75:476-83.

9 Haegeli $\mathrm{P}$, Falk $\mathrm{M}$, Brugger $\mathrm{H}$, et al. Comparison of avalanche survival patterns in Canada and Switzerland. CMAJ 2011;183:789-95. 
10 Hohlrieder $\mathrm{M}$, Brugger $\mathrm{H}$, Schubert $\mathrm{HM}$, et al. Pattern and severity of injury in avalanche victims. High Alt Med Biol 2007;8:56-61.

11 Mclntosh SE, Grissom CK, Olivares CR, et al. Cause of death in avalanche fatalities. Wilderness Environ Med 2007;18:293-7.

12 Falk M, Brugger H, Adler-Kastner L. Avalanche survival chances. Nature 1994;368:21.

13 Grissom CK. Lessons learned from avalanche survival patterns. CMAJ 2011;183: E366-7.

14 Mair $\mathrm{P}$, Brugger $\mathrm{H}$, Mair $\mathrm{B}$, et al. Is extracorporeal rewarming indicated in avalanche victims with unwitnessed hypothermic cardiorespiratory arrest? High Alt Med Biol 2014;15:500-3.

15 Moroder L, Mair B, Brugger $\mathrm{H}$, et al. Outcome of avalanche victims with out-of-hospital cardiac arrest. Resuscitation 2015;89:114-18.

16 Boue Y, Payen JF, Brun J, et al. Survival after avalanche-induced cardiac arrest. Resuscitation 2014;85:1192-6.

17 Boyd J, Brugger $H$, Shuster M. Prognostic factors in avalanche resuscitation: a systematic review. Resuscitation 2010;81:645-52.

18 Grissom CK, McAlpine JC, Harmston CH, et al. Hypercapnia effect on core cooling and shivering threshold during snow burial. Aviat Space Environ Med 2008;79:735-42.

19 Brugger H, Sumann G, Meister R, et al. Hypoxia and hypercapnia during respiration into an artificial air pocket in snow: implications for avalanche survival. Resuscitation 2003:58:81-8.

20 Grissom CK, Radwin Ml, Harmston $\mathrm{CH}$, et al. Respiration during snow burial using an artificial air pocket. JAMA 2000;283:2266-71.

21 Radwin MI, Grissom CK, Scholand MB, et al. Normal oxygenation and ventilation during snow burial by the exclusion of exhaled carbon dioxide. Wilderness Environ Med 2001;12:256-62.

22 Brugger H, Durrer B, Adler-Kastner L. On-site triage of avalanche victims with asystole by the emergency doctor. Resuscitation 1996;31:11-16.

23 McClung D, Schaerer PA. The avalanche handbook. 3rd edn. Seattle, WA: Mountaineers Books, 2006.

24 Oberhammer R, Beikircher W, Hormann C, et al. Full recovery of an avalanche victim with profound hypothermia and prolonged cardiac arrest treated by extracorporeal re-warming. Resuscitation 2008;76:474-80.

25 Strapazzon G, Nardin M, Zanon P, et al. Respiratory failure and spontaneous hypoglycemia during noninvasive rewarming from 24.7 degrees $C$ ( 76.5 degrees $F$ ) core body temperature after prolonged avalanche burial. Ann Emerg Med 2012;60:193-6.

26 Sumann $G$, Putzer $G$, Brugger $H$, et al. Pulmonary edema after complete avalanche burial. High Alt Med Biol 2012;13:295-6.

27 Stalsberg $\mathrm{H}$, Albretsen C, Gilbert M, et al. Mechanism of death in avalanche victims. Virchows Arch A Pathol Anat Histopathol 1989;414:415-22.

28 Radwin MI. Unburying the facts about avalanche victim pathophysiology. Wilderness Environ Med 2008;19:1-3.

29 Brugger $\mathrm{H}$, Etter HJ, Boyd J, et al. Causes of death from avalanche. Wilderness Environ Med 2009;20:93-6.

30 Wick MC, Weiss RJ, Hohlrieder M, et al. Radiological aspects of injuries of avalanche victims. Injury 2009;40:93-8.

31 Locher T, Walpoth BH. Differential diagnosis of circulatory failure in hypothermic avalanche victims: retrospective analysis of 32 avalanche accidents. Praxis 1996:85:1275-82.

32 Radwin MI, Grissom CK, Giesbrecht G. The rate of cooling during avalanche burial; a "core" issue. Resuscitation 2009;80:956-7; author reply 57-8.

33 Putzer G, Schmid S, Braun P, et al. Cooling of six centigrades in an hour during avalanche burial. Resuscitation 2010;81:1043-4.

34 Grissom CK, Radwin MI, Scholand MB, et al. Hypercapnia increases core temperature cooling rate during snow burial. J Appl Physiol 2004;96:1365-70.

35 Johnston CE, White MD, Wu M, et al. Eucapnic hypoxia lowers human cold thermoregulatory response thresholds and accelerates core cooling. J App/ Physiol 1996:80:422-9.

36 Brugger $\mathrm{H}$, Durrer $\mathrm{B}$, Elsensohn $\mathrm{F}$, et al. Resuscitation of avalanche victims: Evidence-based guidelines of the international commission for mountain emergency medicine (ICAR MEDCOM): intended for physicians and other advanced life support personnel. Resuscitation 2013;84:539-46.

37 Grissom CK, Harmston CH, McAlpine JC, et al. Spontaneous endogenous core temperature rewarming after cooling due to snow burial. Wilderness Environ Med 2010;21:229-35.

38 Zafren K, Giesbrecht GG, Danzl DF, et al. Wilderness medical society practice guidelines for the out-of-hospital evaluation and treatment of accidental hypothermia. Wilderness Environ Med 2014;25:425-45.

39 Tomazin I, Kovacs T, International Commission for Mountain Emergency M. Medical considerations in the use of helicopters in mountain rescue. High Alt Med Biol 2003:4:479-83.

40 Rainer B, Frimmel C, Sumann G, et al. Correlation between avalanche emergencies and avalanche danger forecast in the alpine region of Tyrol. Eur J Emerg Med 2008;15:43-7.

41 Slotta-Bachmayr L. How burial time of avalanche victims is influenced by rescue method: an analysis of search reports from the alps. Nat Hazards 2005;34:341-52.

42 Mair P, Frimmel C, Vergeiner G, et al. Emergency medical helicopter operations for avalanche accidents. Resuscitation 2013;84:492-5.
43 Hohlrieder M, Thaler S, Wuertl W, et al. Rescue missions for totally buried avalanche victims: conclusions from 12 years of experience. High Alt Med Biol 2008;9:229-33.

44 Haegeli $P$, Falk M, Procter $E$, et al. The effectiveness of avalanche airbags. Resuscitation 2014:85:1197-203.

45 Hohlrieder M, Mair P, Wuertl W, et al. The impact of avalanche transceivers on mortality from avalanche accidents. High Alt Med Biol 2005;6:72-7.

46 Jamieson B, Haegeli P, Gauthier D. Avalanche cccidents in Canada, Volume 5; Volumes 1996-2007. Canadian Avalanche Association, 2010.

47 Edgerly $\mathrm{B}$. The $\mathrm{ABCS}$ (and D) of digging: avalanche shoveling distilled to the basics. Avalanche Rev 2010;29.

48 Genswein M, Eide R. The V-Shaped snow conveyor-belt an efficient excavation method in avalanche rescue. Proceedings of ISSW 2008. Whistler, BC, Canada, 2008

49 Paal $\mathrm{P}$, Milani $\mathrm{M}$, Brown $\mathrm{D}$, et al. Termination of cardiopulmonary resuscitation in mountain rescue. High Alt Med Biol 2012;13:200-8.

50 Giesbrecht GG, Hayward JS. Problems and complications with cold-water rescue. Wilderness Environ Med 2006;17:26-30

51 Brugger $\mathrm{H}$, Durrer B, International Commission for Mountain Emergency M. On-site treatment of avalanche victims ICAR-MEDCOM-recommendation. High Alt Med Biol 2002:3:421-5.

52 Henriksson O, Lundgren P, Kuklane K, et al. Protection against cold in prehospita care: evaporative heat loss reduction by wet clothing removal or the addition of a vapor barrier - a thermal manikin study. Prehosp Disaster Med 2012;27:53-8.

53 Thomassen 0 , Faerevik $\mathrm{H}$, Osteras $\mathrm{O}$, et al. Comparison of three different prehospital wrapping methods for preventing hypothermia-a crossover study in humans. Scand J Trauma Resusc Emerg Med 2011;19:41.

54 Henriksson 0, Lundgren JP, Kuklane K, et al. Protection against cold in prehospital care-thermal insulation properties of blankets and rescue bags in different wind conditions. Prehosp Disaster Med 2009:24:408-15.

55 Reades R, Studnek JR, Vandeventer $\mathrm{S}$, et al. Intraosseous versus intravenous vascular access during out-of-hospital cardiac arrest: a randomized controlled trial. Ann Emerg Med 2011;58:509-16.

56 Luks AM, Swenson ER. Pulse oximetry at high altitude. High Alt Med Biol 2011:12:109-19.

57 Hayward JS, Eckerson JD. Physiological responses and survival time prediction for humans in ice-water. Aviat Space Environ Med 1984:55:206-11.

58 Rogers IR, O'Brien DL, Wee C, et al. Infrared emission tympanic thermometers cannot be relied upon in a wilderness setting. Wilderness Environ Med 1999:10:201-3.

59 Strapazzon G, Procter E, Paal P, et al. Pre-hospital core temperature measurement in accidental and therapeutic hypothermia. High Alt Med Biol 2014;15:104-11.

60 Perkins GD, Lall R, Quinn T, et al. Mechanical versus manual chest compression for out-of-hospital cardiac arrest (PARAMEDIC): a pragmatic, cluster randomised controlled trial. Lancet 2015:385:947-55.

61 Rubertsson S, Lindgren E, Smekal D, et al. Mechanical chest compressions and simultaneous defibrillation vs conventional cardiopulmonary resuscitation in out-of-hospital cardiac arrest: the LINC randomized trial. JAMA 2014:311:53-61.

62 Mair $P$, Kornberger $E$, Furtwaengler $W$, et al. Prognostic markers in patients with severe accidental hypothermia and cardiocirculatory arrest. Resuscitation 1994;27:47-54

63 Lockey DJ, Lyon RM, Davies GE. Development of a simple algorithm to guide the effective management of traumatic cardiac arrest. Resuscitation 2013;84:738-42.

64 Michenfelder JD, Milde JH. The relationship among canine brain temperature, metabolism, and function during hypothermia. Anesthesiology 1991;75:130-6.

65 Althaus U, Aeberhard P, Schupbach P, et al. Management of profound accidental hypothermia with cardiorespiratory arrest. Ann Surg 1982;195:492-5.

66 Mark E, Jacobsen 0 , Kjerstad A, et al. Hypothermic cardiac arrest far away from the center providing rewarming with extracorporeal circulation. Int J Emerg Med 2012;5:7.

67 Hilmo J, Naesheim T, Gilbert M. "Nobody is dead until warm and dead": prolonged resuscitation is warranted in arrested hypothermic victims also in remote areas-a retrospective study from northern Norway. Resuscitation 2014;85:1204-11.

68 Meyer M, Pelurson N, Khabiri E, et al. Sequela-free long-term survival of a 65-year-old woman after 8 hours and 40 minutes of cardiac arrest from deep accidental hypothermia. J Thorac Cardiovasc Surg 2014;147:e1-2

69 [No authors listed]. Battlefield Advanced Trauma Life Support (BATLS). J R Army Med Corps 2001;147:314-21.

70 American College of Surgeons Committee on Trauma. Advanced trauma life support for doctors ATLS : manuals for coordinators and faculty. 8th edn. Chicago, IL: American College of Surgeons, 2008.

71 National Association of Emergency Medical Technicians (U.S.). Pre-Hospital Trauma Life Support Committee, American College of Surgeons. Committee on Trauma. PHTLS : Prehospital Trauma Life Support. 7th edn. St. Louis, Mo: Mosby Jems/Elsevier, 2011.

72 Durrer B, Brugger H, Syme D, International Commission for Mountain Emergency $M$. The medical on-site treatment of hypothermia: ICAR-MEDCOM recommendation. High Alt Med Biol 2003;4:99-103.

73 Brown DJ, Brugger H, Boyd J, et al. Accidental hypothermia. N Engl J Med 2012;367:1930-8.

74 Hayward JS, Collis M, Eckerson JD. Thermographic evaluation of relative heat loss areas of man during cold water immersion. Aerosp Med 1973;44:708-11. 